\title{
SPECIAL ISSUE: UNDERSTANDING AND RESPONDING TO PAIN- BASED BEHAVIOUR IN CHILD AND YOUTH CARE WORK
}

\section{Issue editors: James P. Anglin and Lilia M. Zaharieva}

We are grateful to Dr. Sibylle Artz, Editor of the International Journal of Child, Youth and Family Studies, for the invitation to produce a special issue on pain-based behaviour in child and youth care work. Since the term was created and published in 2002 (Anglin, 2002), the notion has entered the literature, the research, and, perhaps most importantly, the practice of child and youth care internationally. The eight articles in this issue come from Ireland, Australia, the United States, and Canada, and offer a broad range of perspectives.

After receiving the invitation to compile this issue, we scanned the recent child and youth care literature and readily identified 13 publications — articles and books — using the term painbased behaviour. There are undoubtedly many more, however we believed the authors of these publications would present a significant cross-section of perspectives on understanding and responding to pain and pain-based behaviour. We are excited and honoured that the authors represented here were able to contribute articles to this issue.

The first article by Larry Brendtro is vintage Brendtro. Readers of this journal will be familiar with the extensive publications and international training seminars Larry has contributed to the field over the past 50 years. In fact, 2019 is the 50th anniversary of the classic publication The Other 23 Hours that Larry co-authored with Alfred Trieschman and James Whittaker (Trieschman, Whittaker, \& Brendtro, 1969) when Larry and James were graduate students. Since that time, Larry has kept abreast of the child-related literature across many disciplines, including education, psychology, sociology, juvenile justice, and brain science, continually searching for the core elements of human development and the helping professions that need to be understood, preserved, and further developed through research and innovative practice. In his article, he offers a multi-disciplinary tour de force in which he explores a broad range of psychosocial issues and perspectives in an integrative manner. He also considers the historical evolution of key concepts and suggests that children's emotional pain derives from unmet needs.

Modestly, we placed our own co-authored article second in the roster. This article is presented in largely a dialogical format, reflecting the process that produced it. In 2017, Jim was asked to do the opening morning for a two-day Norwegian mental health conference titled "Expressions of Pain" based on his research. As outlined in the article, Jim then approached Lilia to engage in a literature-informed experiential conversation weekly over four months in order to explore more deeply the notion of pain-based behaviour. We hope that our contribution may assist others to find ways to bridge the worlds of youth with lived experience in care and the worlds of 
International Journal of Child, Youth and Family Studies (2019) 10(2-3): 1-4

professional helpers, perhaps resulting in "binocular vision" encompassing both inside-out and outside-in experiences and perspectives.

Heather Modlin's article introduces Robert Kegan's cognitive-developmental theory through her research on supervision in residential child and youth care with a focus on worker mindset development. Kegan's work provides a well-researched approach to assessing people's ability to manage complexity and ambiguity, two central dimensions of child and youth care work. Heather's study revealed two quite different approaches to understanding and responding to pain and pain-based behaviour depending on the cognitive-developmental level of the workers (i.e., those with a socialized versus those with a self-authoring cognitive system). Her insights provide valuable information for those managing programs or working in supervision roles, as well as for educators and trainers seeking to enhance the skills of practitioners and the functioning of child welfare agencies. We anticipate that many readers of this article will want to access Heather's doctoral dissertation (Modlin, 2018) on which her article is based, as well as perhaps consult some of Kegan's publications.

In the following article, Martha Holden and Debbie Sellers of the Bronfenbrenner Centre for Translational Research at Cornell University provide an overview of a new residential care program model (CARE) designed to strengthen an agency's capacity to respond to young people's trauma, pain, and pain-based behaviour through creating developmental and therapeutic experiences. This principle-based model requires leadership and supervision characteristic of a self-authoring mindset (as explored by Modlin, above), and is implemented through a holistic and agency-wide process. All staff, whatever their positions in the agency, need to be congruent in their commitment to and application of the core CARE principles. Rigorous research, some of which is presented in the article, has resulted in the CARE approach being classified by the California Evidence-Based Clearing House for Child Welfare as a promising practice that is highly relevant for residential care work.

Maurice Fenton follows with his deeply reflective analysis of his journey in residential care work, and especially his encounters with pain and the process of personal and professional development required to become an effective worker and supervisor over a 28-year career. Maurice models for other practitioners an openness and commitment to learning based in humility, transparency, and persistence. He demonstrates how one's personal struggles with pain and loss need to be understood as important aspects of professional growth. As editors, we had the privilege of witnessing Maurice's growth as he wrote his way to completing this article, with each draft incorporating new insights and creative linkages. We expect that further articles will emerge from Maurice based on the excellent material that had to be left out of this one.

Moving from the Irish context to the state of Victoria, Australia, Annette Jackson, Raeleen McKenzie, and Margarita Frederico present a new emotional-relief first aid tool using the acronym PAIN (Predicting and Preparing; Acknowledging and putting words to feelings; Informing, and Nurturing and Noticing). The authors explore the invisibility of psychoemotional pain, some of 
the neuroscientific basis for understanding pain, and the challenges of people trying to articulate their pain to others. Their innovative approach to supporting children, families, and workers is accompanied by some step-by-step practice-based examples, emphasizing the importance of learning to apply theory in day-to-day child and youth care practice. They also highlight the movement across Australia to develop therapeutic residential care (TRC) to respond more effectively to the needs of children in out-of-home care.

Next, another Australian, Howard Bath, shines a spotlight on an aspect of trauma-induced pain too often overlooked or ignored in the literature and practice: shame. Howard has for many years conducted workshops and training sessions on trauma and trauma-informed practice, and has co-authored a recent book, The Three Pillars of Transforming Care: Trauma and Resilience in the Other 23 Hours (Bath \& Seita, 2018). Howard takes a thoughtful and research-informed approach to his work while always focussing on the needs of children and the needs of the practitioners who work with them. His emphasis on creating environments of safety, relational connections, and coping skills is infused with the wisdom of practice experience that makes his writing accessible to practitioners, trainers, and researchers alike.

The final article by James Anglin and Angela Scott addresses some critical issues relating to researching pain. The two authors share aspects of their learning as researchers that both challenged them personally and led to important insights in their research studies. The authors draw on the little-known work of George Devereux (1967) to suggest that social science research, especially that of a qualitative nature, always involves the researcher in very personal ways in both the data-gathering and the data-analysis processes. When researching pain, researchers need to be prepared to experience their own pain, and to view this aspect as a valuable and necessary part of understanding the pain of others. In brief, social research is intervention, and involves re-searching the researcher as well as engaging intimately with others.

\section{Summary}

Many common threads weave themselves across the eight articles in this issue, including (to mention but a few) the centrality of relationships, especially loving ones; the transgenerational nature of trauma; the importance of naming our pains and having a language of pain; the need for shared and reciprocal connections; the integration of mind, body, spirit, and brain; the ecological and contextual nature of pain-based behaviour; the challenges of complexity and ambiguity; the stresses of caring in painful situations; the positive uses of pain experiences; and the imperative for human growth and healing involving children, families, researchers, practitioners, and communities.

As co-editors, we have learned much from each and every article in this issue, and we hope readers will share our feeling that we are not just better informed, but are somewhat better people for the experience. 
International Journal of Child, Youth and Family Studies (2019) 10(2-3): 1-4

\section{References}

Anglin, J. P. (2002). Pain, normality and the struggle for congruence: Reinterpreting residential care for children and youth. New York, NY: Routledge.

Bath, H., \& Seita, J. (2018). The three pillars of transforming care: Trauma and resilience in the other 23 hours. Winnipeg, MB: Faculty of Education Publishing, University of Winnipeg.

Devereux, G. (1967). From anxiety to method in the behavioral sciences. Paris, France: Mouton $\&$ Co.

Modlin, H. (2018). Exploring the experiences of child and youth care workers in residential care through a constructive-developmental lens (Doctoral dissertation). University of Victoria, Victoria, BC. Retrieved from: https://dspace.library.uvic.ca/handle/1828/160

Trieschman, A. R., Whittaker, J. K., \& Brendtro, L.K. (1969). The other 23 hours: Child-care work with emotionally disturbed children in a therapeutic milieu. New York, NY: Aldine de Gruyter. 